\title{
DESIGUALDADES EDUCACIONAIS EM CONTEXTOS URBANOS: UM ESTUDO DA GEOGRAFIA DE OPORTUNIDADES EDUCACIONAIS NA CIDADE DO RIO DE JANEIRO
}

\author{
MARIANE CAMPELO KOSLINSKI* \\ FÁTIMA ALVES ${ }^{* *}$ \\ WOLFRAM JOHANNES LANGE***
}

\begin{abstract}
RESUMO: O objetivo do trabalho é trazer uma contribuição teórica dos estudos da sociologia urbana, bem como a contribuição metodológica das análises espaciais (georreferenciamento), para analisar as desigualdades educacionais em grandes centros urbanos. Ao integrar a dimensão das desigualdades educacionais às dinâmicas de segregação residencial desses centros, traz questões até então subdimensionadas nos estudos sobre desigualdades educacionais. Como estratégia analítica, selecionamos a cidade do Rio de Janeiro para exemplificar as potencialidades da abordagem teórico-metodológica adotada. As análises reuniram informações de diferentes bases de dados, tais como Prova Brasil (2011) e Censo Escolar (2011). Por fim, o artigo discute experiências recentes de políticas educacionais que utilizam instrumentos de geoprocessamento e/ou que focalizam escolas em territórios vulneráveis e suas consequências para distribuição de oportunidades educacionais.
\end{abstract}

Palavras-chave: Desigualdades educacionais. Geografia de oportunidades educacionais. Segregação residencial.

\section{EDUCATIONAL INEQUALITIES IN URBAN CONTEXTS: A STUDY OF} THE GEOGRAPHY OF EDUCATIONAL OPPORTUNITIES IN RIO DE JANEIRO

ABSTRACT: This article intends to bring out a theoretical contribution from urban sociology studies, as well as a methodological contribution using social-spatial analysis (geocoding) to analyse educational inequalities in large urban centers. It integrates the dimension of educational inequalities and the dynamics of residential segregation in urban centers in order to deal with questions that were, up to now, not frequently considered in the studies about

Faculdade de educação da Universidade Federal do Rio de Janeiro (UFRJ). Rio de Janeiro (RJ) Brasil.

** Departamento de Educação da Pontifícia Universidade Católica do Rio de Janeiro (PUC-Rio). Rio de Janeiro (RJ) - Brasil.

*** Universidade de Ciências Aplicadas de Colônia - Alemanha.

Contato com os autores: <mckoslinski@gmail.com> 
Desigualdades educacionais em contextos urbanos...

educational inequality. As an analytical strategy, we have selected the city of Rio de Janeiro to observe the potentialities of the theoretical-methodological approach adopted. The analyses have used information from different databases (Prova Brasil 2011, Censo Escolar, 2011). In the concluding remarks, the article discusses recent experiences in educational policies that have used geocoding tools and/or focused on schools in vulnerable territories and their consequences on the distribution of educational opportunities.

Key words: Educational inequalities. Geography of educational opportunities. Residential segregation.

\section{INÉGALITÉS SCOLAIRES DANS DES CONTEXTES URBAINS: UNE ÉTUDE DE LA GÉOGRAPHIE D' OPPORTUNITES SCOLAIRES A RIO DE JANEIRO}

RÉSUMÉ: L'objectif du travail est apporter une contribution théorique des études de la sociologie urbaine, ainsi que de la contribution méthodologique des analyses spatiales (géoréférenciation), pour analyser les inégalités scolaires dans de grands centres urbains. Quand on intégre la dimension des inégalités scolaires aux dynamiques de ségrégation résidentielle de centres urbains, des questions, jusqu'à présent sousdimensionées, sont mises en évidence dans les études sur des inégalités scolaires. Comme stratégie analytique, nous sélectionnons la municipalité de Rio de Janeiro pour exemplifier les potentialités de l'abordage théorie-methodologique adopté. Les analyses ont rassemblé des informations de différentes bases de données, tels comme Prova Brésil (2011) et Recensement Scolaire (2011). Finalement, l'article discute des expériences récentes de politiques scolaires qui utilisent des instruments de géotraitement et/ou focalisent des écoles sur des territoires vulnérables et leurs conséquences pour la distribution d'opportunités scolaires.

Mots-clés: Inégalités scolaires. Géographie d'opportunités scolaires. Ségrégation résidentielle.

\section{Introdução}

A

s desigualdades sociais e educacionais brasileiras são amplas e multifacetadas. Diversos estudos já se debruçaram nas diferentes formas em que as desigualdades se manifestam - seja a partir da dualidade rural versus urbano, sistema público versus privado, entre ou dentro dos sistemas públicos e/ou entre as regiões geográficas brasileiras (COSTA; KOSLINSKI; COSTA, 2012; ALVES; FRANCO, 2008; PADILHA et al. 2012; KOSLINSKI et al., 2010). Também são variadas as dimensões ou parâmetros que são utilizados para ilustrar as desigualdades educacionais: englobando desde estudos que focalizam insumos - como a infraestrutura das escolas (SÁTYRO; SOARES, 2007; SOARES; SÁTYRO, 2008) e a distribuição de recursos financeiros (PINTO, 2007) - até aqueles que focalizam resultados escolares tais como proficiência, fluxo e trajetórias escolares (ALVES; FRANCO, 2008; SOARES; SÁTYRO, 2008).

O objetivo do presente trabalho é trazer uma contribuição teórica dos estudos da sociologia urbana, bem como a contribuição metodológica das análises espaciais 
(georreferenciamento), para analisar as desigualdades educacionais em grandes centros urbanos. Especificamente, o foco é revelar as microdesigualdades dentro das redes públicas de uma mesma cidade. Isso é particularmente importante quando consideramos a dimensão educacional dentro da complexa teia de interrelações que caracterizam os centros urbanos: local de moradia, transporte, acesso aos bens culturais, segurança, entre outros. Ao integrar a dimensão das desigualdades educacionais às dinâmicas de segregação residencial desses centros urbanos, estamos trazendo à tona questões que até então estavam subdimensionadas nos estudos sobre desigualdades educacionais. Apenas alguns exemplos: mecanismos perversos de acesso, alocação e transferência de alunos, distribuição de recursos educacionais, alocação e movimentação dos docentes, abertura e fechamento de escolas e transferência de alunos/matrículas entre diferentes redes de ensino em uma mesma cidade. Certamente, este artigo não poderá tratar de todas essas temáticas. Até mesmo porque muitos dados não estão disponíveis.

O artigo discute, em sua primeira parte, algumas contribuições do campo da sociologia urbana para o desenvolvimento de estudos que focalizam processos relacionados à disposição da geografia de oportunidades ou às desigualdades de oferta educacionais em grandes cidades e/ou em regiões metropolitanas. Em seguida, como estratégia analítica, seleciona a cidade do Rio de Janeiro para exemplificar as potencialidades da abordagem teórico-metodológica adotada. Para tanto, analisa a distribuição da geografia de oportunidades educacionais a partir da espacialização de indicadores educacionais, focalizando as seguintes dimensões: contexto social dos alunos, condições de infraestrutura e funcionamento da escola, expectativa docente e resultados escolares. Nas considerações finais, o trabalho discute algumas experiências recentes de políticas educacionais que utilizam instrumentos de geoprocessamento e/ou que focalizam escolas localizadas em territórios mais vulneráveis e suas possíveis consequências.

\section{Segregação residencial e geografia de oportunidades educacionais: o impacto sobre a oferta educacional}

Trabalhos anteriores analisaram de forma detalhada como a sociologia urbana foi recentemente incorporada à discussão de distribuição de oportunidades educacionais no contexto internacional e, mais recentemente, no contexto brasileiro (JENCKS; MAYER, 1990; BROOKS-GUNN; DUNCAN; ABER, 1997; RIBEIRO; KAZTMAN, 2008; RIBEIRO et al., 2010). Em trabalhos anteriores, discutimos a relação entre segregação residencial e desigualdades de oportunidades educacionais a partir de uma extensa bibliografia que parte dos seguintes conceitos: o efeito-vizinhança e o conceito de geografia de oportunidades (KOSLINSKI; ALVES, 2012; KOSLINSKI; LASMAR; ALVES, 2012; RIBEIRO; KOSLINSKI, 2010). 
O presente estudo não pretende realizar uma revisão exaustiva dessa bibliografia, mas pretende discutir, brevemente, as seguintes questões: Por que falar sobre desigualdades nas grandes cidades? Quais os mecanismos geradores de desigualdades de oportunidades em tais contextos, em especial, desigualdades de oferta escolar?

Grosso modo, podemos reduzir ou simplificar as explicações sobre as desigualdades educacionais no contexto urbano a partir dos seguintes mecanismos:

\section{Figura 1}

Mecanismos que influenciamas desigualdades educacionais em contextos urbanos

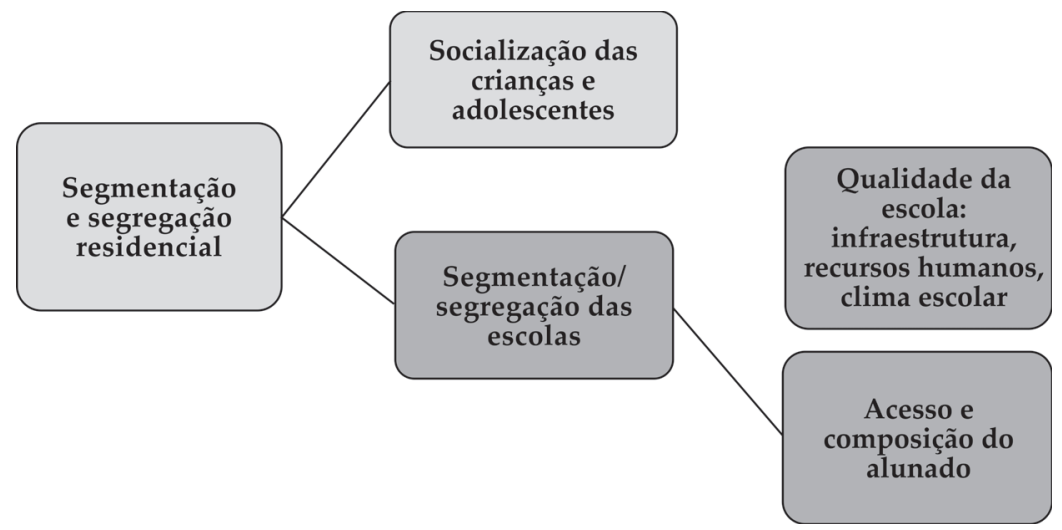

A partir do trabalho de Wilson (1987), observamos grande proliferação de estudos que tratam dos impactos da segregação residencial sobre as oportunidades individuais (SMALL; NEWMAN, 2001; ELLEN; TURNER, 1997). O autor explica essa relação a partir do mecanismo de isolamento social, resultante da concentração de pobreza nas áreas centrais das grandes cidades norte-americanas. Para tratar especificamente do impacto da segregação residencial sobre oportunidades educacionais, o esquema apresentado na Figura 1 parte da divisão de fatores mediadores proposta por Jencks e Mayer (1990): mecanismos de socialização e mecanismos institucionais.

Os mecanismos mediadores relacionados a processos de socialização são mais frequentemente mencionados por estudos que usam características da vizinhança para estimar resultados escolares (BROOKS-GUNN; DUNCAN; ABER, 1997; CRANE, 1991; ELLEN; TURNER, 1997). Nessa abordagem as vizinhanças e bairros são tratados como espaços geográficos que comportam relações e redes sociais e, portanto, seriam esferas intermediárias de socialização entre a família e a escola. Dessa 
forma, a segregação residencial - e a consequente concentração de pobreza em certas vizinhanças - levaria ao isolamento e restrição de redes sociais de crianças e adolescentes. As restrições de redes com seus pares e com adultos de outras classes seriam foco das explicações a partir de modelos epidêmicos ou efeito-pares e de modelos de papel social, respectivamente (JENCKS; MAYER, 1990; ELLEN; TURNER, 1997; CRANE, 1991).

Já os mecanismos mediadores relacionados aos modelos institucionais partem do pressuposto de que os indivíduos podem ser afetados pela qualidade dos serviços que são oferecidos em suas vizinhanças. Proponentes desse modelo focalizam principalmente a qualidade, quantidade e diversidade de instituições presentes em uma dada comunidade/vizinhança, capazes de suprir as necessidades de crianças e adolescentes tais como bibliotecas, escolas, pré-escolas, facilidade médicas, entre outras (JENCKS; MAYER, 1990; ELLEN; TURNER, 1997; FLORES, 2008).

A desigualdade na distribuição de instituições escolares nos contextos urbanos é considerada, de um lado, a partir das dimensões de infraestrutura, recursos humanos e expectativas dos professores e, de outro, a partir da composição do alunado. Isto é, as trajetórias e resultados escolares dos indivíduos seriam afetados não somente por processos de socialização na vizinhança, como também pelo acesso desigual a escolas de qualidade.

Parte da bibliografia sobre efeito-vizinhança também associa mecanismos institucionais aos processos de socialização. Entretanto, neste caso, tais mecanismos não são tradados a partir de modelos de papel social de adultos residentes na vizinhança/bairro, mas a partir de um padrão de socialização exercido por adultos que trabalham em instituições localizadas nos bairros caracterizados por concentração de pobreza (JENCKS; MAYER, 1990). De um lado, bairros segregados teriam menor capacidade de envolver a comunidade com as questões da escola (LOPEZ, 2008). De outro, essa abordagem argumenta que as expectativas dos professores quanto ao futuro escolar dos alunos variam de acordo com a vizinhança em que a escola está localizada e o local de moradia dos alunos (FLORES, 2008; LOPEZ, 2008). É importante ressaltar esse aspecto, uma vez que estudos em eficácia escolar postulam que a expectativa dos professores exerce impacto sobre o sucesso escolar dos alunos (BROOKE; SOARES, 2008).

Outros estudos discutem o impacto da segregação residencial sobre os recursos físicos e humanos das escolas. Por exemplo, Ellen e Turner (1997) argumentam que a desigualdade da distribuição de serviços locais é um dos principais mecanismos através dos quais o efeito vizinhança opera. Escolas localizadas em áreas menos afluentes da cidade teriam menos recursos pedagógicos, menos apoio voluntário dos pais e professores com menos experiência e, assim, enfrentariam maiores problemas com a gestão (ELLEN; TURNER, 1997; FLORES, 2008). Nessas vizinhanças, 
crianças também seriam afetadas pela baixa oferta ou disponibilidade local de préescolas públicas. De forma similar, Ainsworth (2002) e Jencks e Mayer (1990) argumentam que escolas localizadas em áreas mais abastadas ou mistas seriam mais bem-sucedidas em contratar e manter professores mais qualificados (AINSWORTH, 2002; JENCKS; MAYER, 1990). Já as escolas em áreas de concentração de pobreza experimentariam maior rotatividade de professores.

Os estudos realizados por Kaztman $(2001,2012)$ em contextos urbanos latinoamericanos oferecem explicações que nos ajudam a compreender os processos através dos quais a segregação residencial exerce impacto sobre a oferta de equipamentos educacionais. De forma similar aos estudos norte-americanos, a autor relaciona a segregação residencial ao isolamento social, ou à probabilidade de formação de espaços de sociabilidade informal entre indivíduos de diferentes origens socioeconômicas. Para o autor, segregação é definida a partir da presença de espaços que comportam diferenciação, baixa interação (segmentação), bem como a vontade ou a ação de membros de diferentes categorias sociais de manter ou elevar as barreiras que os separam (KAZTMAN, 2001).

O menor contato entre pessoas de clivagens sociais diferentes, característico dos contextos urbanos latino-americanos, levaria a um esgarçamento do tecido social. As barreiras socioterritoriais impostas à interação entre grupos de diferentes origens socioeconômicas e/ou raciais resultariam na incapacidade de formação de identidades coletivas amplas e de alianças para exercer voz ou defesa de interesses e direitos (KAZTMAN, 2012). Ou seja, tais grupos, separados geograficamente nas grandes cidades, perdem uma base comum para reivindicação de bens e serviços públicos. Tal fato explicaria a relação entre o isolamento social, decorrente da segregação residencial, e a distribuição desigual de equipamentos escolares.

Por fim, outra importante dimensão da segmentação escolar diz respeito ao impacto da segregação residencial sobre a segregação escolar. Isto é, o padrão de segregação residencial condicionaria a composição do alunado, em termos socioeconômicos e raciais, nas escolas localizadas em diferentes áreas das grandes cidades. Este é um ponto de extrema relevância para o mapeamento de oportunidades educacionais, uma vez que estudos sobre o efeito-escola já observaram que o nível socioeconômico e a composição racial das escolas estão fortemente associados aos resultados dos alunos. Estes efeitos seriam especialmente perversos para alunos de menor nível socioeconômico, agrupados em escolas com outros alunos de origem semelhante (COLEMAN, 1966; BROOKE; SOARES, 2008).

Recentemente, estudos têm sido desenvolvidos focalizando o impacto de políticas educacionais e da segregação residencial sobre a segregação escolar. Por exemplo, estudos realizados no contexto norte-americano têm investigado recentes tendências de ressegregação dos distritos escolares (LOGAN, 2004; FRANKENBERG; 
LEE, 2002). ${ }^{1}$ Na conclusão de seu trabalho, Frankenberg e Lee (op. cit.) argumentam que parte do problema da segregação das escolas é de difícil resolução, dado que alguns distritos não são compostos por diferentes grupos raciais.

Outra explicação para a relação entre segregação residencial e segregação escolar em contextos urbanos é proposta por Ben Ayed (2012). Sua investigação, realizada no contexto francês, mostrou que os departamentos mais urbanizados frequentemente apresentaram sob-êxito da aprendizagem dos alunos. Também apresentaram maior dispersão do desempenho das escolas e alta correlação do desempenho com a porcentagem de alunos em situação de precariedade. O estudo propõe que a relação entre a segregação residencial, característica dos territórios urbanos, e as desigualdades de oportunidades educacionais também pode ser compreendida a partir da lógica da competição: as áreas de sob-êxito seriam marcadas por descontinuidade e as áreas prioritárias seriam estigmatizadas, levando a práticas de competição e evitment scolaiere, gerando desigualdades na composição do alunado.

No entanto, se Ben Ayed (2012) argumenta que, para evitar seleção, seria necessário evitar competição entre as escolas, outros estudos argumentam que a competição ou a livre escolha (school choice) não necessariamente trazem maior "polarização", "estratificação" ou "guetificação" das escolas. Por exemplo, os estudos de Taylor e Gorard (2001) e Gorard, Taylor e Fitz (2003) observaram uma menor segregação escolar a partir de 1988 com a introdução do sistema de escolha de estabelecimentos escolares no contexto da Grã-Bretanha. Por outro lado, as reformas introduzidas em $1998^{2}$ - que reduziram a escolha dos pais e privilegiaram o acesso a partir do critério de distância entre casa-escola - teriam agravado o impacto da segregação residencial sobre a estratificação das escolas. Por fim, os autores chamam atenção para a importância de separar os impactos de políticas educacionais de outras barreiras para a mobilidade social e concluem: "[...] the segregation in the school system could be largely a result of wider residential segregation, and where you live therefore becomes a key determinant of your life chances" (TAYLOR; GORARD, 2001, p. 1830).

Como pontuado em trabalhos anteriores (KOSLINSKI; ALVES, 2012; ALVES; LANGE; BONAMINO, 2010), outra forma de pensar a relação entre segregação residencial e a oferta da educação é a partir do conceito de geografia de oportunidades. Essa abordagem se assemelha ao modelo institucional proposto por estudos de efeito-vizinhança, uma vez que também considera que o local de moradia pode afetar as oportunidades e resultados dos indivíduos. O enfoque da geografia de oportunidades (GALSTER; KILLEN, 1995) conjuga o impacto da segregação residencial sobre a geografia objetiva (distribuição de instituições, mercados, bens e serviços) com a geografia subjetiva de oportunidades (valores, anseios, preferências e percepções 
subjetivas das oportunidades). Ambas apresentariam grande variação geográfica nos contextos das grandes cidades. Considerando o objeto foco do presente estudo, poderíamos argumentar que a geografia objetiva de oportunidades, condicionada pelo local de moradia dos alunos, seria um dos elementos centrais para compreender a tomada de decisões de atores sociais como, por exemplo, a escolha e as possibilidades de acesso às escolas públicas que apresentam características e qualidade diferentes.

No entanto, mesmo frente à recente expansão da discussão das desigualdades educacionais em contextos urbanos (RIBEIRO; KAZTMAN, 2008; RIBEIRO et al., 2010; ÉRNICA; BATISTA, 2012; PADILHA et al., 2012), são poucos os esforços no sentido de identificar a distribuição de geografia de oportunidades educacionais no contexto brasileiro.

O estudo de Torres et al. (2008), por exemplo, apresenta um panorama das desigualdades de oferta educacional na cidade de São Paulo, a partir das dimensões infraestrutura (uniforme, quadras, bibliotecas, sala de informática, entre outros), recursos humanos (qualificação e experiência de diretores) clima escolar (atitudes, expectativas dos professores em relação aos alunos). $\mathrm{O}$ artigo identificou um menor tempo de permanência dos alunos em escolas localizadas nas periferias da cidade. Também observou que as áreas mais pobres recebem profissionais com menor qualificação e menor experiência e, mais frequentemente, sofrem com rotatividade desses profissionais. ${ }^{3}$ Por fim, mostrou o baixo estímulo de professores: "desrespeito e desinteresse em relação aos alunos negros, pobres, favelados e residentes na periferia" (TORRES et al., 2008, p. 85).

Em outro estudo, Torres e Gomes (2002) identificam padrões de desigualdade de desempenho educacional a partir de uma dimensão espacial nos municípios da Região Metropolitana de São Paulo. O estudo mostra uma alta correlação entre desempenho escolar dos alunos na prova de língua portuguesa ${ }^{4}$ e a média de escolaridade dos responsáveis por domicílios dos setores censitários em que as escolas estão localizadas. No entanto, nos trabalhos já mencionados, os indicadores educacionais não são especializados e, portanto, não é possível observar o padrão da distribuição de escolas na cidade ou na Região Metropolitana de São Paulo.

Estudo realizado por Soares et al. (2008) apresenta o padrão de distribuição das escolas no território do município de Belo Horizonte, utilizando indicadores de nível socioeconômico das famílias dos alunos e indicadores de qualidade e equidade das escolas. ${ }^{5} \mathrm{O}$ estudo observou que a distribuição dos alunos de acordo com o nível socioeconômico (NSE) dos pais segue a dinâmica de segregação da cidade (as escolas localizadas nas áreas centrais e mais abastadas da cidade tendem a receber alunos com NSE mais alto). Escolas das favelas localizadas nas zonas sul e leste da cidade apresentaram os indicadores mais baixos de qualidade, mesmo que em algumas áreas menos favorecidas tenham apresentado indicadores de qualidade acima 
da média municipal. Estas análises foram feitas a partir da média das escolas localizadas nos limites de cada Unidade Espacial Homogênea (UEH), unidade territorial mais abrangente que os bairros. Essa metodologia é diferente da espacialização contínua utilizada no presente estudo, que é mais precisa em mostrar as oportunidades educacionais disponíveis para alunos que residem em diferentes áreas da cidade.

Por fim, o estudo de Alves, Lange e Bonamino (2010) mapeou a geografia objetiva de oportunidades educacionais na cidade do Rio de Janeiro a partir do Índice de Oportunidades Educacionais. O índice combina as dimensões demanda de crianças de 6 a 14 anos e oferta de escolas de ensino fundamental. Como no presente estudo, os autores utilizam ferramentas de geoprocessamento (SIG) para especializar o índice e oportunidades educacionais. As análises apresentadas observaram que as áreas críticas, que apresentam oportunidades limitadas (concentram alta ou média demanda e baixa oferta), estão localizadas predominantemente nas grandes favelas da cidade.

\section{Geografia de oportunidades e oferta escolar no contexto da cidade do Rio de Janeiro}

Como mencionado anteriormente, o presente trabalho parte da discussão de estudos sobre segregação residencial e pretende trazer, além de uma contribuição teórica, uma contribuição metodológica, através de análises espaciais (georreferenciamento), para compreender a desigualdades de oportunidades educacionais em contextos urbanos. Como estratégia analítica, selecionamos a cidade do Rio de Janeiro para exemplificar as potencialidades da abordagem teórico-metodológica adotada.

Antes de apresentar a abordagem metodológica e os resultados do trabalho, é necessário apresentar, brevemente, certas características do modelo de segregação da cidade do Rio de Janeiro, que não se esgota no padrão centro-periferia presente em outras grandes cidades brasileiras.

O mapa 1, a seguir, mostra a distribuição do Índice de Desenvolvimento Social (IDS) para a cidade do Rio de Janeiro. O IDS é um índice composto pelas se-

guintes dimensões: a) acesso ao saneamento básico; b) qualidade da habitação; c) grau de escolaridade e d) disponibilidade de renda. Os resultados mostram que, na cidade do Rio de Janeiro, encontramos um modelo de segregação complexo: em uma primeira análise, observamos um modelo centro - periferia, caracterizado pela presença de uma região na qual se concentram os maiores IDS e outra com índices muito baixos. Já em uma análise mais aprofundada, percebem-se as especificidades dentro das regiões da cidade. Uma característica da cidade do Rio de Janeiro é a presença de favelas, com baixo desenvolvimento social, em áreas nobres da cidade. No 
entanto, encontramos também, nas áreas de baixo desenvolvimento social, regiões com alto desenvolvimento.

\section{Mapa 1}

Distribuição do Índice de Desenvolvimento Social na cidade do Rio de Janeiro

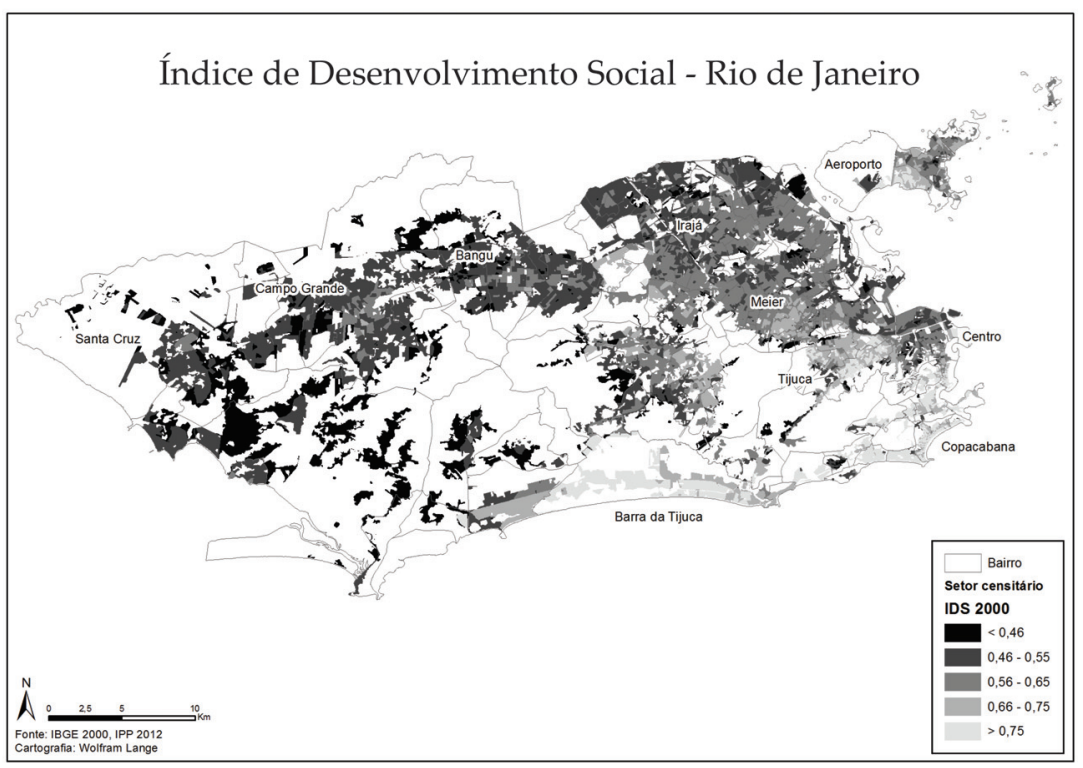

\section{Abordagem metodológica}

As análises desenvolvidas reuniram informações de diferentes bases de dados e foi desenvolvida utilizando ferramentas de análises socioespaciais. A partir das respostas aos questionários contextuais da Prova Brasil 2011 para alunos, diretores e professores, bem como das informações coletadas no Censo Escolar 2011, desenvolveu-se um conjunto de indicadores que englobam dimensões da educação. São elas: contexto social dos alunos, condições de infraestrutura e funcionamento da escola, expectativa docente e resultados escolares. Foram desenvolvidos indicadores para o nível da escola para o $5^{\circ}$ ano e para o $9^{\circ}$ ano do ensino fundamental, separadamente.

A escolha desta estratégia deve-se ao fato de que diversos estudos mostram que existe uma grande diferenciação entre as etapas do ensino fundamental. Cabe ressaltar que esta diferenciação deve ser analisada conjuntamente com a responsabilidade do estado ou do município em cada uma das etapas de ensino. Este não é o caso do Rio de Janeiro, uma vez que a rede municipal é responsável por quase 
toda a matrícula pública do ensino fundamental. No entanto, é essa a realidade que encontramos em muitos centros urbanos, como Curitiba, Belo Horizonte e São Paulo. A Tabela 1 apresenta a descrição e a fonte de dados dos indicadores utilizados nas análises.

\section{Tabela 1}

Descrição dos indicadores utilizados

\begin{tabular}{|c|c|c|}
\hline Indicador & Fonte & Descrição \\
\hline $\begin{array}{l}\text { Desempenho em } \\
\text { Matemática }\end{array}$ & $\begin{array}{l}\text { Prova cognitiva em } \\
\text { Matemática - Prova } \\
\text { Brasil } 2011\end{array}$ & $\begin{array}{l}\text { Média por escola do desempenho em Matemática dos } \\
\text { alunos. }\end{array}$ \\
\hline $\begin{array}{l}\text { Desempenho em } \\
\text { Língua Portuguesa }\end{array}$ & $\begin{array}{l}\text { Prova cognitiva em } \\
\text { Língua Portuguesa - } \\
\text { Prova Brasil } 2011\end{array}$ & $\begin{array}{l}\text { Média por escola do desempenho em Língua Portu- } \\
\text { guesa dos alunos. }\end{array}$ \\
\hline $\begin{array}{l}\text { Percentual de } \\
\text { alunos nos níveis } \\
\text { básico ou abaixo em } \\
\text { Matemática }\end{array}$ & $\begin{array}{l}\text { Prova cognitiva em } \\
\text { Matemática - Prova } \\
\text { Brasil } 2011\end{array}$ & $\begin{array}{l}\text { Porcentagem de alunos por escola que obtiveram de- } \\
\text { sempenho igual ou inferior a } 225 \text { pontos na escala de } \\
\text { proficiência de Matemática para o } 5^{-} \text {ano e } 300 \text { para } \\
\text { o } 9^{\circ} \text { ano. }\end{array}$ \\
\hline $\begin{array}{l}\text { Percentual de } \\
\text { alunos nos níveis } \\
\text { básico ou abaixo em } \\
\text { Língua Portuguesa }\end{array}$ & $\begin{array}{l}\text { Prova cognitiva em } \\
\text { Língua Portuguesa - } \\
\text { Prova Brasil } 2011\end{array}$ & $\begin{array}{l}\text { Porcentagem de alunos por escola que obtiveram de- } \\
\text { sempenho igual ou inferior a } 200 \text { pontos na escala de } \\
\text { proficiência de Língua Portuguesa para } 5^{\circ} \text { ano e } 275 \\
\text { para o } 9^{\circ} \text { ano. }\end{array}$ \\
\hline $\begin{array}{l}\text { Escolaridade } \\
\text { dos pais }\end{array}$ & $\begin{array}{l}\text { Questionário dos } \\
\text { alunos da Prova } \\
\text { Brasil } 2011\end{array}$ & $\begin{array}{l}\text { Porcentagem de alunos por escola, cujos pais apresen- } \\
\text { tam escolaridade igual ou superior ao ensino médio } \\
\text { completo. Utilizou-se a máxima educação da mãe e } \\
\text { do pai. }\end{array}$ \\
\hline $\begin{array}{l}\text { Problemas que } \\
\text { prejudicam o } \\
\text { funcionamento da } \\
\text { escola }\end{array}$ & $\begin{array}{l}\text { Questionário dos } \\
\text { Diretores } \\
\text { da Prova Brasil } 2011\end{array}$ & $\begin{array}{l}\text { Medida contínua (média } 0 \text { desvio padrão } 1 \text { ) obtida a } \\
\text { partir de análise fatorial das informações sobre carên- } \\
\text { cias de recursos financeiros, recursos humanos, recur- } \\
\text { sos pedagógicos e de problemas disciplinares e com } \\
\text { falta de professores e alunos, na percepção dos dire- } \\
\text { tores. Valores altos significam maior percepção de que } \\
\text { estes problemas foram prejudiciais ao funcionamento } \\
\text { da escola e valores baixos indicam menor percepção. } \\
\text { Alpha de Combrach: } 0.70 \text {. Questões } 55 \text { a } 64 \text { do ques- } \\
\text { tionário dos diretores. }\end{array}$ \\
\hline $\begin{array}{l}\text { Condições de } \\
\text { Infraestrutura }\end{array}$ & $\begin{array}{l}\text { Questionário do } \\
\text { Censo Escolar } 2011\end{array}$ & $\begin{array}{l}\text { Medida contínua (média } 0 \text { desvio padrão } 1 \text { ) obtida } \\
\text { a partir de análise fatorial das informações sobre a } \\
\text { presença de sala de professores, laboratório de infor- } \\
\text { mática, laboratório de ciências, quadra de esportes, } \\
\text { biblioteca/sala de leitura. Valores positivos indicam } \\
\text { condições adequadas e valores negativos indicam } \\
\text { condições inadequadas. Alpha de Combrach }=0.60 \text {. }\end{array}$ \\
\hline $\begin{array}{l}\text { Expectativas } \\
\text { docentes }\end{array}$ & $\begin{array}{l}\text { Questionário dos } \\
\text { professores da Prova } \\
\text { Brasil } 2011\end{array}$ & $\begin{array}{l}\text { Porcentagem de professores por escola que afirmam } \\
\text { que quase todos ou pouco mais da metade dos seus } \\
\text { alunos ingressarão na universidade. }\end{array}$ \\
\hline
\end{tabular}


A criação dos mapas envolveu ferramentas de geoprocessamento a partir de um Sistema da Informação Geográfica (SIG). Em vez de calcular a média dos indicadores das escolas por bairro, as análises seguiram algoritmos espaciais baseados em dados matriciais (raster). Dados de raster representam fenômenos espaciais em uma matriz de células organizada em linhas e colunas. Cada célula representa um pixel e cada pixel tem um valor. Um algoritmo de análise espacial, como estatísticas de vizinhança, pode ser aplicado para cada célula que forma essa matriz. No caso da análise desse estudo, o algoritmo busca por todas as escolas em um raio de 1.500 metros de cada célula, calcula a média do indicador definido dessas escolas e atribui esse valor ao pixel. O resultado é um mapa da distribuição da média do indicador que é independente de delimitações administrativas do espaço urbano.

\section{Resultados}

Os mapas 2 e 3 apresentam as distribuições do percentual por escola dos alunos cujos pais têm escolaridade acima do ensino médio para o $5^{\circ}$ ano e do $9^{\circ}$ ano do ensino fundamental, respectivamente. Observa-se que o padrão é o mesmo que o encontrado para a distribuição do IDS, no Mapa 1. Seguramente essa similaridade se deve ao fato de que, no Brasil, educação e renda (e, consequentemente, condições e local de moradia) são altamente correlacionadas. Uma vez que as análises de escolaridade dos pais incluem somente alunos das escolas das redes públicas de ensino, é de se esperar contrastes menores na comparação com o IDS, mas mesmo assim evidenciamos escolas com uma porcentagem elevada de alunos cujos pais têm alta escolaridade. Na cidade do Rio de Janeiro, em 2011, $33,9 \%$ dos alunos matriculados em escolas públicas de $5^{\circ}$ ano e $46,9 \%$ daqueles matriculados no $9^{\circ}$ ano tinham pais com ensino médio ou ensino superior. No Brasil, $58 \%$ dos alunos das redes públicas de ensino possuem pais com ensino fundamental incompleto. Do outro lado, encontramos escolas com baixa porcentagem de alunos cujos pais têm alta escolaridade e grande parte dessas escolas está concentrada nas áreas menos abastadas da cidade.

Com relação ao desempenho médio das escolas nas disciplinas de Matemática e Língua Portuguesa (mapas 4 e 5 para o $5^{\circ}$ ano e mapas 6 e 7 para o 9 o ano do ensino fundamental), observa-se que a distribuição é novamente convergente com o padrão dos indicadores sociais apresentados anteriormente $\mathrm{Na}$ geografia da cidade, as áreas periféricas e as comunidades situadas nos bairros mais abastados do Rio de Janeiro apresentam resultados inferiores à área central e aos bairros nobres. O cenário é semelhante para as disciplinas e para os segmentos de ensino. 


\section{Mapa 2}

Porcentagem de alunos por escola, cujos pais apresentam escolaridade igual ou superior ao ensino médio na cidade do Rio de Janeiro $-5^{\circ}$ ano do ensino fundamental

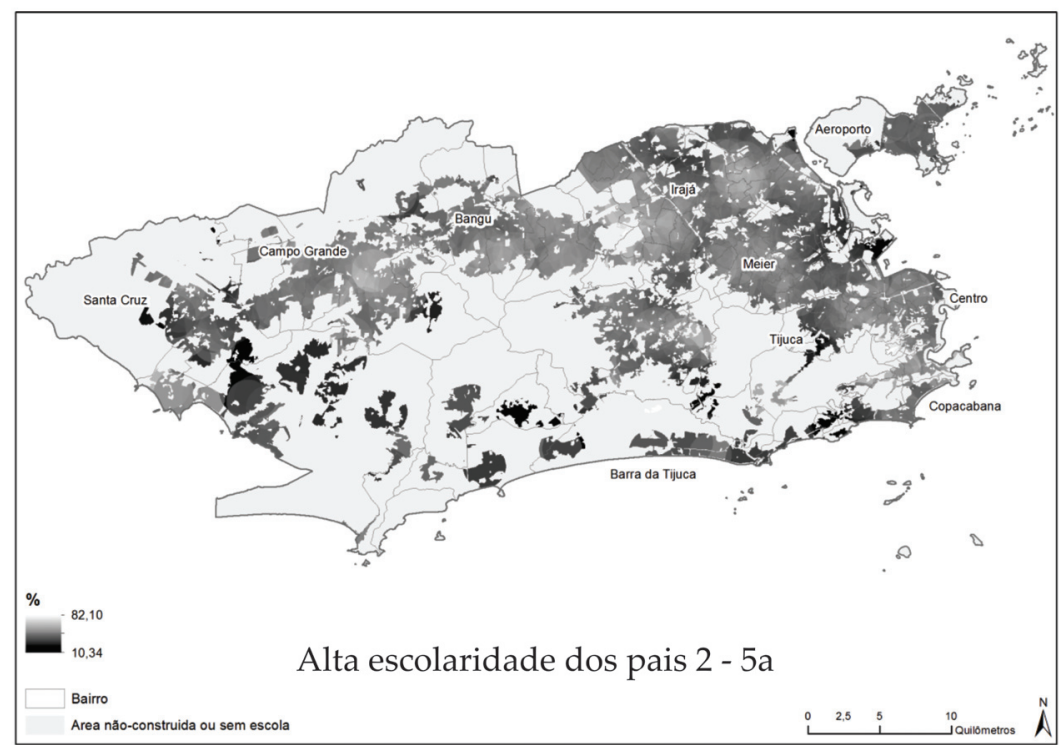

\section{Mapa 3}

Porcentagem de alunos por escola cujos pais apresentam escolaridade igual ou superior ao ensino médio na cidade do Rio de Janeiro - $9^{\text {o }}$ ano do ensino fundamental

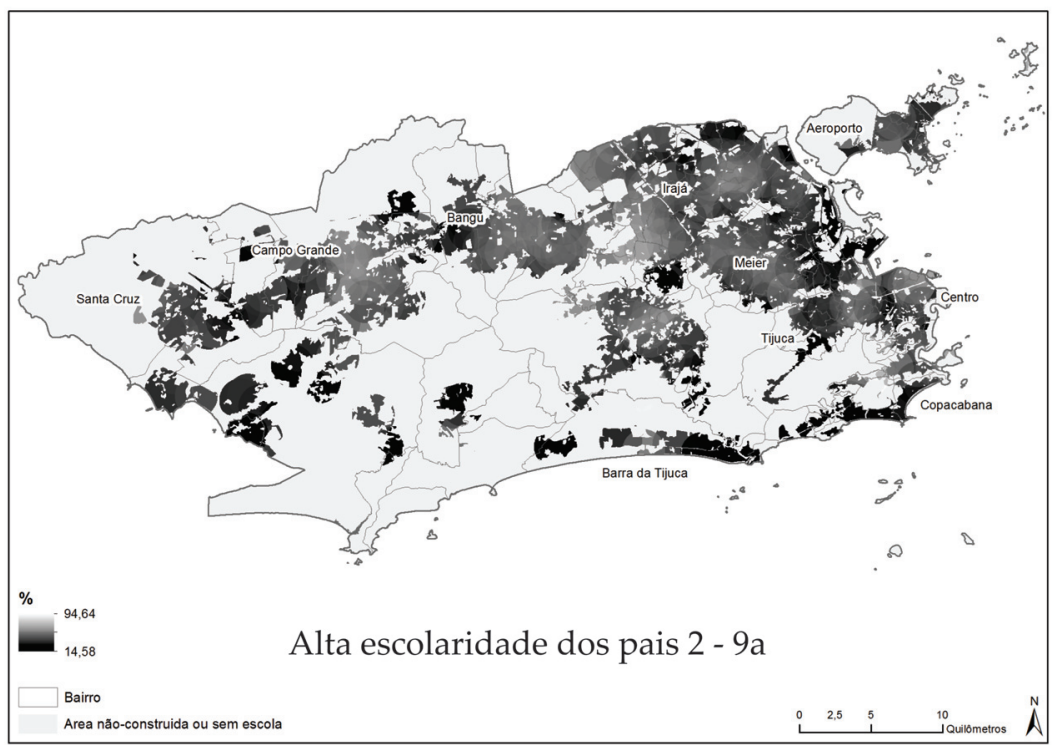

Fonte: Prova Brasil 2011. Elaboração dos autores 


\section{Mapa 4}

Distribuição do desempenho médio das escolas em Matemática na cidade do Rio de Janeiro $-5^{\circ}$ ano do ensino fundamental

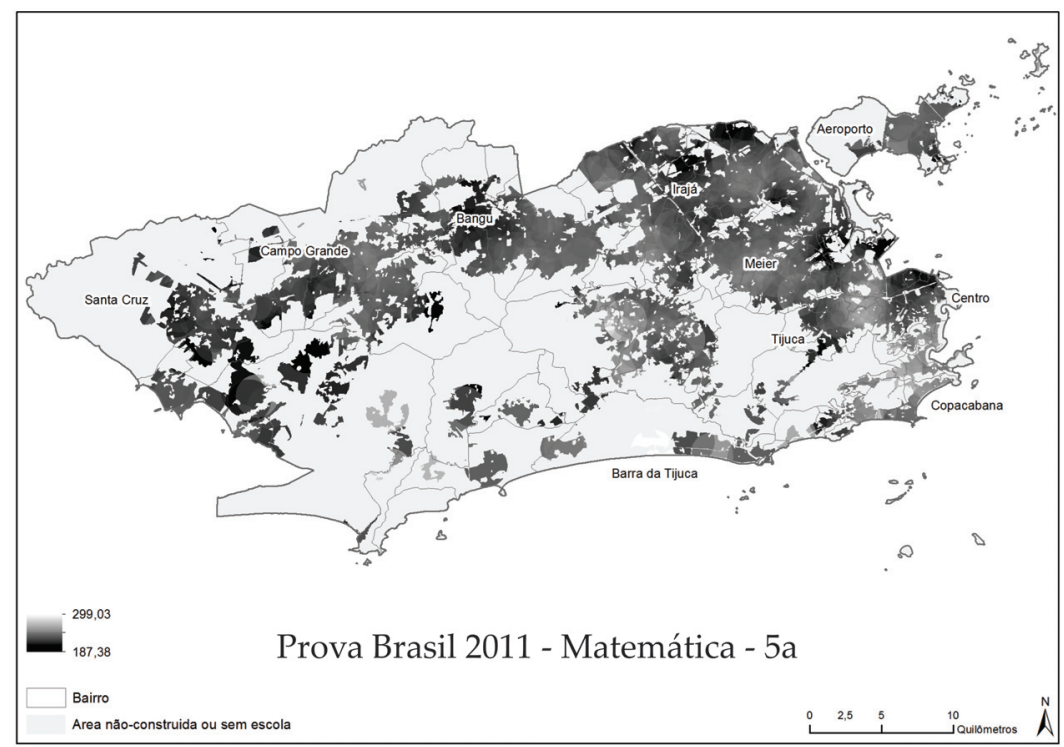

Fonte: Prova Brasil 2011. Elaboração dos autores.

\section{Mapa 5}

Distribuição do desempenho médio das escolas em Língua Portuguesa na cidade do Rio de Janeiro - 5⿳0 ano do ensino fundamental

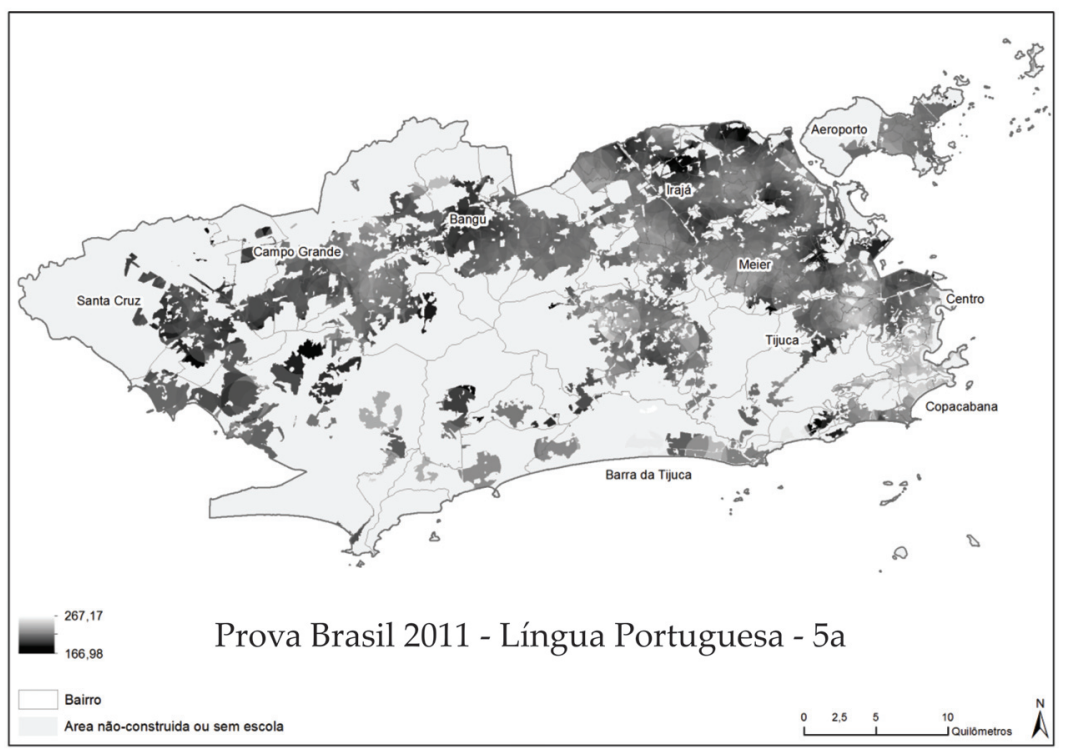




\section{Mapa 6}

Distribuição do desempenho médio das escolas em Matemática na cidade do Rio de Janeiro $-9^{\circ}$ ano do ensino fundamental

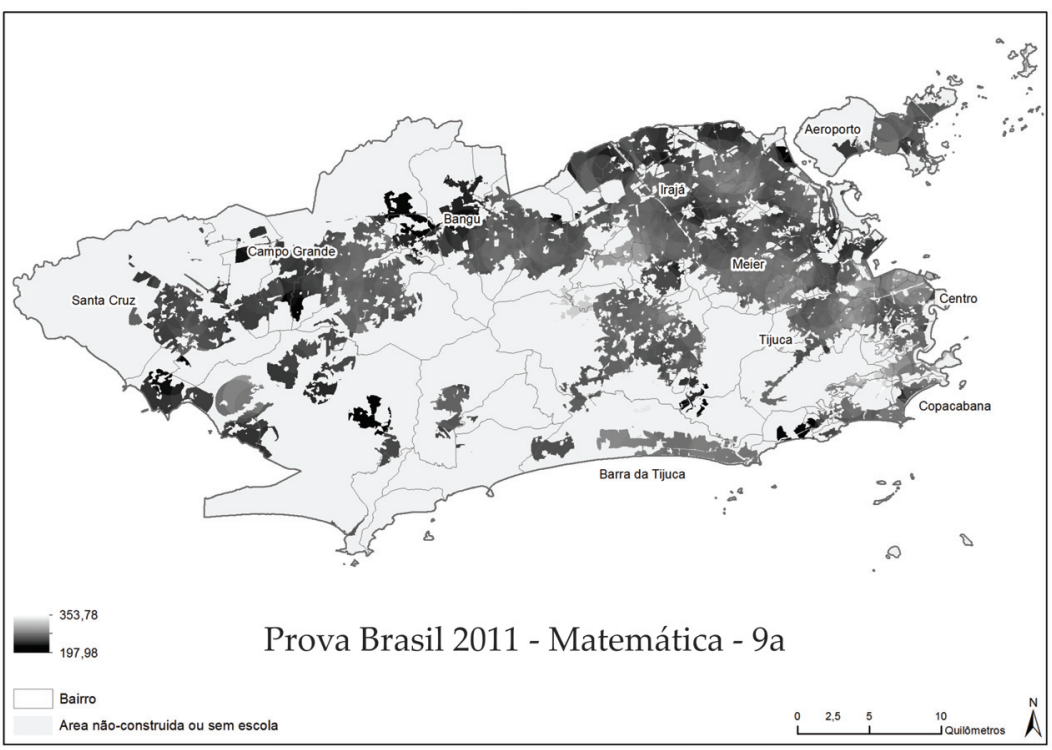

\section{Mapa 7}

Distribuição do desempenho médio das escolas em Língua Portuguesa na cidade do Rio de Janeiro - 9º ano do Ensino Fundamental

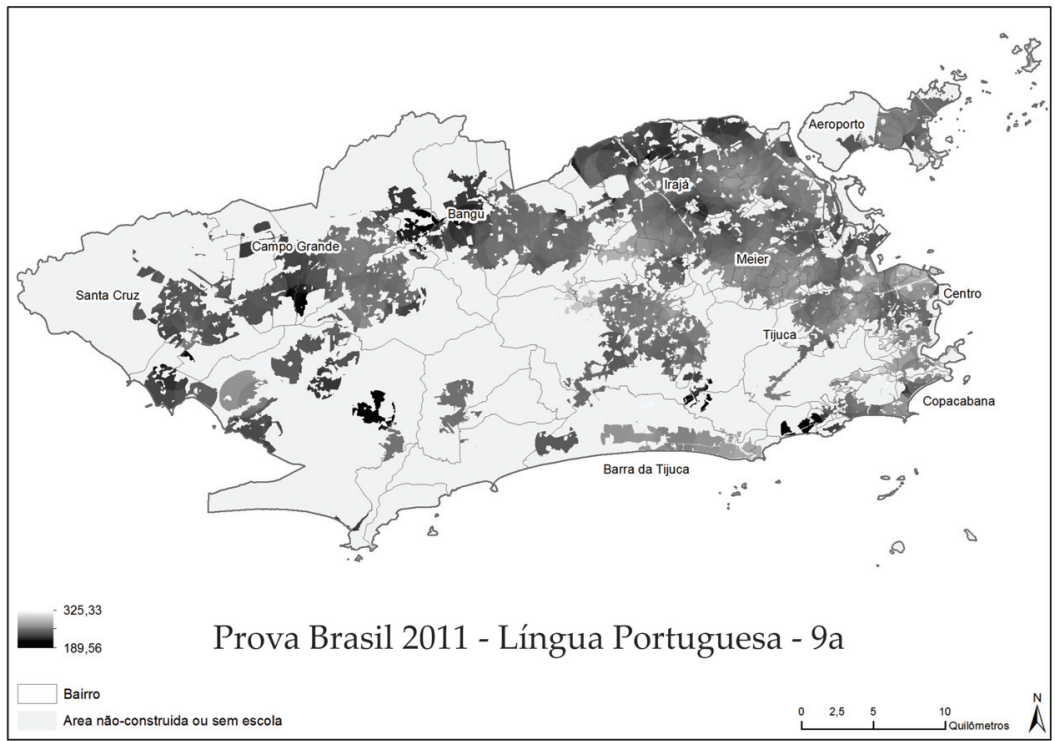

Fonte: Prova Brasil 2011. Elaboração dos autores 
A análise conjunta dos mapas com a evolução das médias na Prova Brasil para a cidade do Rio de Janeiro (Tabela 2) sinaliza que, em 2011, houve um crescimento, especialmente para a disciplina de Matemática em relação a 2009: 10,32 pontos no 5ำ ano e 6,39 no $9^{\circ}$ ano do ensino fundamental. Já para Língua Portuguesa, o crescimento foi de apenas 4,58 pontos e 0,56 pontos para o $5^{\circ}$ ano e $9^{\circ}$ ano, respectivamente. Este modesto crescimento pode sinalizar uma melhoria dos resultados escolares na cidade, mesmo que não no ritmo desejável. No entanto, os mapas mostram como esta média apresenta uma distribuição desigual. Em áreas menos abastadas, a média da região pode estar afastada da média da cidade, em Matemática: quase 40 pontos no $5^{\circ}$ ano e quase 55 pontos no $9^{\circ}$ ano do ensino fundamental. Esses resultados não são diferentes na comparação com as demais edições da Prova Brasil.

\section{Tabela 2}

Média do desempenho na Prova Brasil na cidade do Rio de Janeiro por segmento de ensino e disciplina - 2005 a 2011

\begin{tabular}{|l|l|r|r|r|r|}
\hline \multicolumn{2}{|c|}{} & 2005 & 2007 & 2009 & 2011 \\
\hline $5^{\circ}$ ano do ensino & Língua Portuguesa & 183,20 & 178,02 & 197,48 & 202,36 \\
fundamental & Matemática & 190,00 & 194,10 & 217,19 & 227,51 \\
\hline $9^{0}$ ano do ensino & Língua Portuguesa & 233,40 & 236,09 & 246,32 & 246,88 \\
fundamental & Matemática & 248,60 & 244,09 & 246,40 & 252,79 \\
\hline
\end{tabular}

Fonte: Inep.

Com o que vimos até agora, não dá para negar a relação entre segregação residencial e segregação escolar, no que diz respeito à composição social do alunado e dos resultados nas avaliações. É o padrão de desigualdade entre escolas amplamente registrado na literatura sociológica. Nesse sentido, torna-se relevante investigar como as regras de matrículas, bem como os processos internos de transferências de alunos, por exemplo, podem estar contribuindo para este cenário. Por outro lado, é igualmente importante um olhar mais aprofundado de como as recentes políticas de pacificação das comunidades e de atendimento prioritário e especializado em escolas situadas em áreas vulneráveis, implementadas na cidade do Rio de Janeiro, estão associadas com os padrões de desigualdades, especialmente no que se refere à composição do alunado nas escolas.

Além do problema da diferença dos resultados entre as escolas (eficácia), não podemos deixar de considerar também às questões relacionadas à equidade. Em outras palavras, precisamos analisar qual é a distribuição de desempenho entre os alunos que frequentam a mesma escola. Isso é particularmente importante de se verificar, uma vez que, frequentemente, eficácia não vem acompanhada de equidade. Pelo contrário, o acirramento da iniquidade dentro de uma escola pode resultar 
em melhoras de resultados. Nesta perspectiva, ao invés de analisar as médias de desempenho das escolas, utilizamos como indicador a distribuição dos alunos pelos níveis de proficiência. Para a construção do nosso indicador partimos da proposta de Soares (2009), resumida na tabela a seguir.

\section{Tabela 3}

Níveis de desempenho por ano de ensino e por disciplina

\begin{tabular}{|l|l|l|l|l|}
\hline & \multicolumn{2}{|c|}{ Língua Portuguesa } & \multicolumn{2}{c|}{ Matemática } \\
\hline & 5 o ano & $9^{\circ}$ ano & 5 o ano & $9^{\circ}$ ano \\
\hline Abaixo do Básico & $<150$ & $<200$ & $<175$ & $<225$ \\
\hline Básico & Entre 150 e 200 & Entre 200 e 275 & Entre 175 e 225 & Entre 225 e 300 \\
\hline Adequado & Entre 200 e 250 & Entre 275 e 325 & Entre 225 e 275 & Entre 300 e 350 \\
\hline Avançado & Acima de 250 & Acima de 325 & Acima de 275 & Acima de 350 \\
\hline
\end{tabular}

Fonte: Soares (2009).

Os mapas 8 e 9 mostram a distribuição dos alunos do $5^{\circ}$ ano do ensino fundamental, nos níveis abaixo do básico e no básico, por escola. Já os mapas 10 e 11 apresentam os dados para o $9^{\circ}$ ano do ensino fundamental. $\mathrm{O}$ padrão de desigualdade segue aos demais mapas mostrados. Áreas com baixos resultados no desempenho apresentam grande porcentagem de alunos nos dois níveis mais baixos da escala de proficiência da Prova Brasil. Em algumas áreas, podem chegar a mais de 75\% dos alunos. Esses alunos estão terminando o $5^{\mathbf{o}}$ ano do ensino fundamental sem a aquisição de habilidades como: selecionar informações explícitas e implícitas correspondentes a um personagem e identificar a finalidade de um texto, no caso, de Língua Portuguesa. Já para Matemática, entre as habilidades não adquiridas estão: leitura de informações e dados apresentados em tabelas e resolução de problemas utilizando sistema monetário brasileiro. No caso do $9^{\circ}$ ano do ensino fundamental, os alunos nestes níveis não são capazes, em Língua Portuguesa, de comparar textos que tratam do mesmo tema, reconhecendo diferentes formas de abordar a informação; em Matemática, de resolver problemas utilizando porcentagens e utilizando unidades de medidas padronizadas $(\mathrm{kg} / \mathrm{g} ; \mathrm{Km} / \mathrm{m} ; 1 / \mathrm{ml})$.

Outro resultado que merece destaque é encontrado comparando os mapas 4 e 6, por exemplo, relacionados à Matemática no $5^{\mathbf{o}}$ ano do ensino fundamental. Algumas áreas da cidade apresentam bons resultados. No entanto, o percentual de alunos nos níveis mais baixos é extremamente elevado. Este é o caso de Copacabana. Essa realidade é mais pronunciada quando analisamos os resultados do $9^{\circ}$ ano do ensino fundamental. 
Desigualdades educacionais em contextos urbanos...

\section{Mapa 8}

Distribuição do percentual de alunos nos níveis básico ou abaixo em Matemática na cidade do Rio de Janeiro $-5^{\circ}$ ano do ensino fundamental

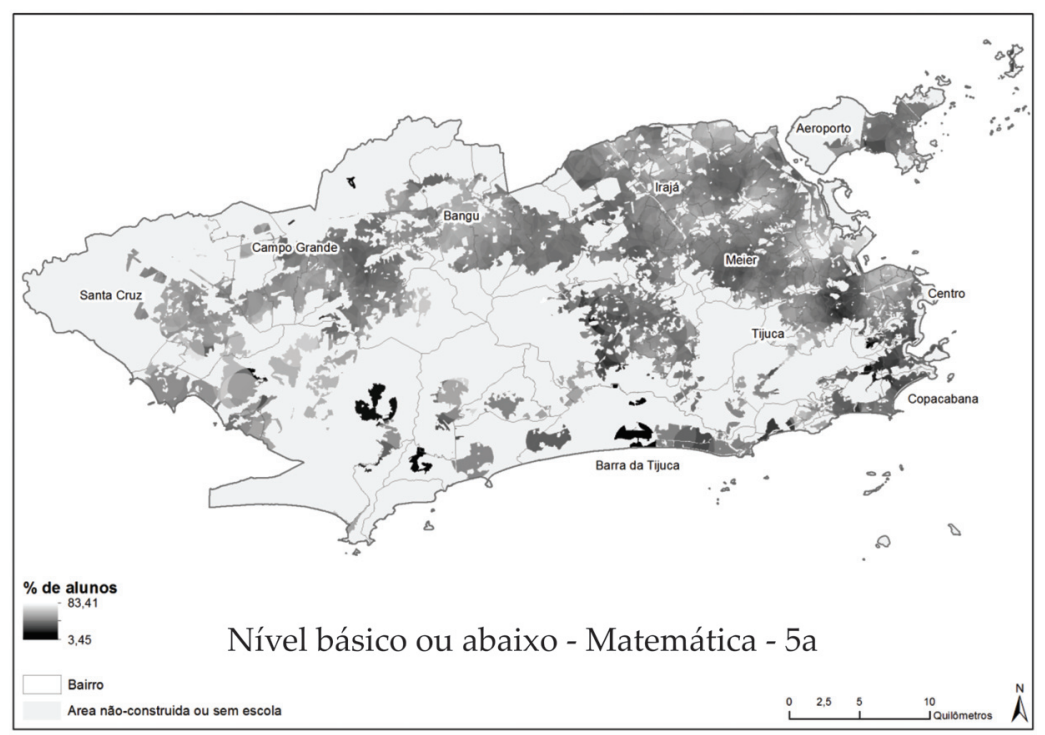

Fonte: Prova Brasil 2011. Elaboração dos autores.

\section{Mapa 9}

Distribuição do percentual de alunos nos níveis básico ou abaixo em Língua Portuguesa na cidade do Rio de Janeiro $-5^{\underline{0}}$ ano do ensino fundamental

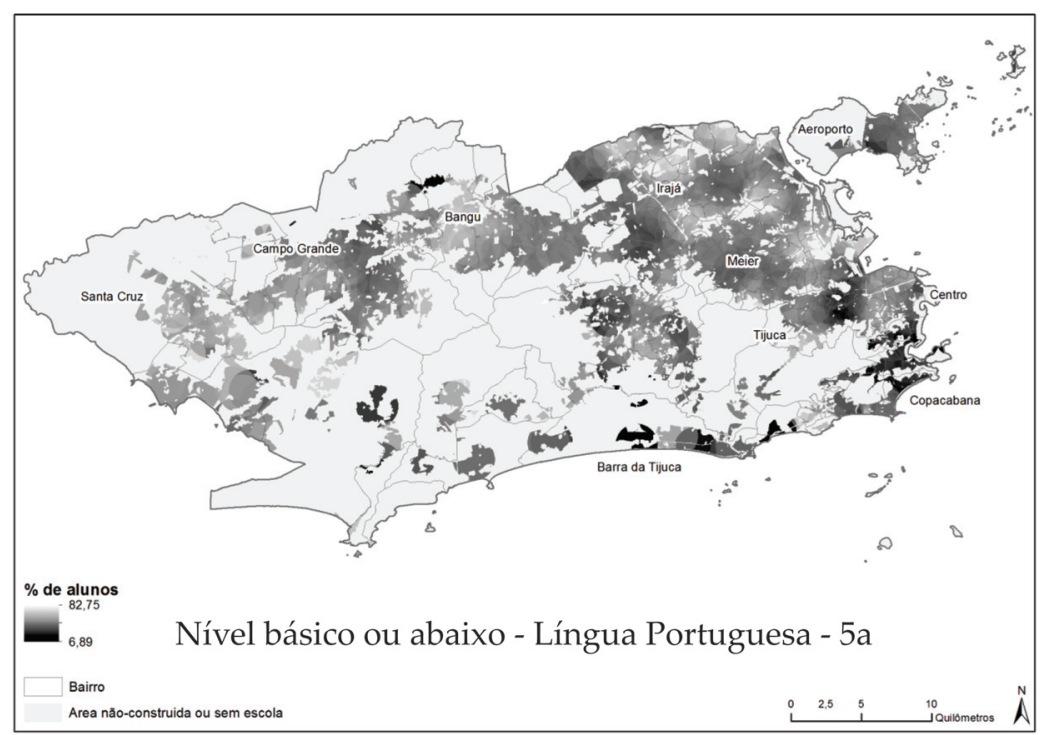

Fonte: Prova Brasil 2011. Elaboração dos autores 


\section{Mapa 10}

Distribuição do percentual de alunos nos níveis básico ou abaixo em Matemática na cidade do Rio de Janeiro - 9o ano do Ensino Fundamental

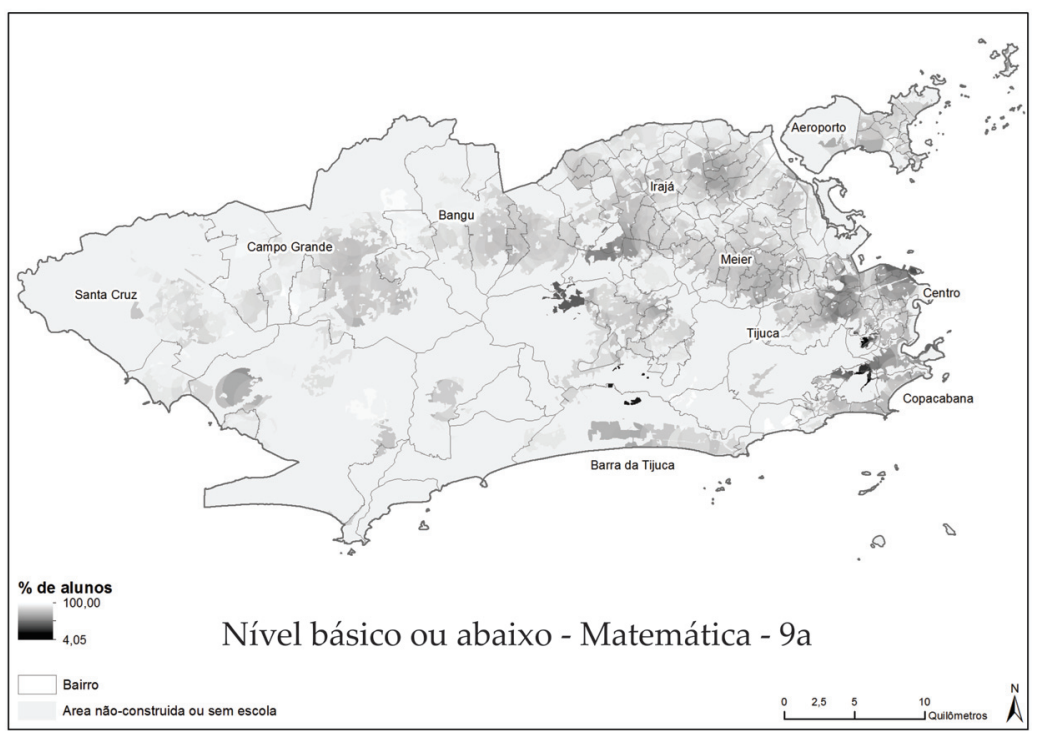

Fonte: Prova Brasil 2011. Elaboração dos autores.

\section{Mapa 11}

Distribuição do percentual de alunos nos níveis básico ou abaixo em Língua Portuguesa na cidade do Rio de Janeiro $-9^{\circ}$ ano do ensino fundamental

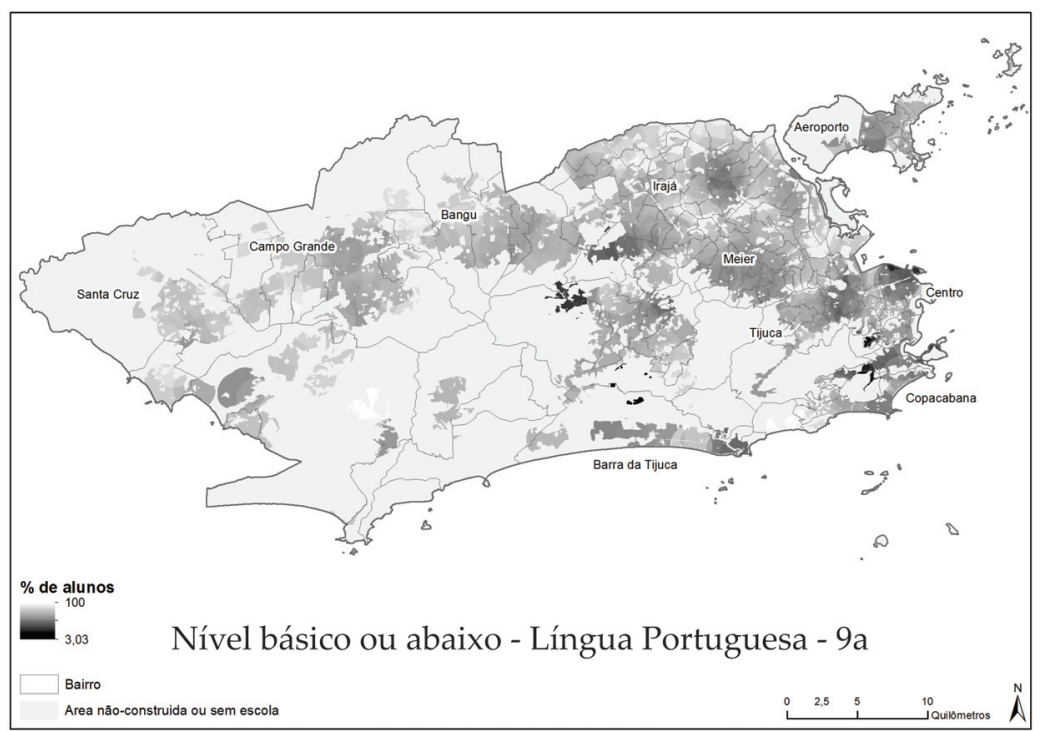

Fonte: Prova Brasil 2011. Elaboração dos autores. 
De forma a analisar a associação entre segregação residencial e recursos físicos das instituições escolares, construímos dois indicadores. O primeiro refere-se às percepções dos diretores sobre o quanto problemas relacionados com a insuficiência de recursos financeiros, falta de professores, rotatividade docente e falta de recursos pedagógicos, entre outros, prejudicaram o funcionamento da escola. Já o segundo indicador está relacionado com a disponibilidade na escola de espaços como biblioteca, quadra de esportes, laboratório de informática e de ciências.

Com relação ao indicador de problemas na escola, os mapas 12 e 13, respectivamente para o $5^{\circ}$ ano e para o $9^{\circ}$ ano do ensino fundamental, mostram uma homogeneidade na sua distribuição. Em quase todas as áreas da cidade, os diretores apontaram que tais problemas não foram prejudiciais para o funcionamento da escola. Essa homogeneidade é maior para os dados do $5^{\circ}$ ano do que para o $9^{\circ}$ ano. Neste caso, as áreas que apresentam maiores problemas são justamente onde estão localizadas as grandes comunidades cariocas. $\mathrm{O}$ indicador de infraestrutura, mapas 14 e 15, apresenta maior heterogeneidade para ambas as séries. Sua distribuição, novamente, indica o seguinte padrão: as áreas periféricas e as comunidades situadas nos bairros mais abastados do Rio de Janeiro comportam piores condições de oferta em termos da infraestrutura escolar.

\section{Mapa 12}

Problemas que prejudicam o funcionamento da escola na cidade do Rio de Janeiro $-5^{\circ}$ ano do ensino fundamental

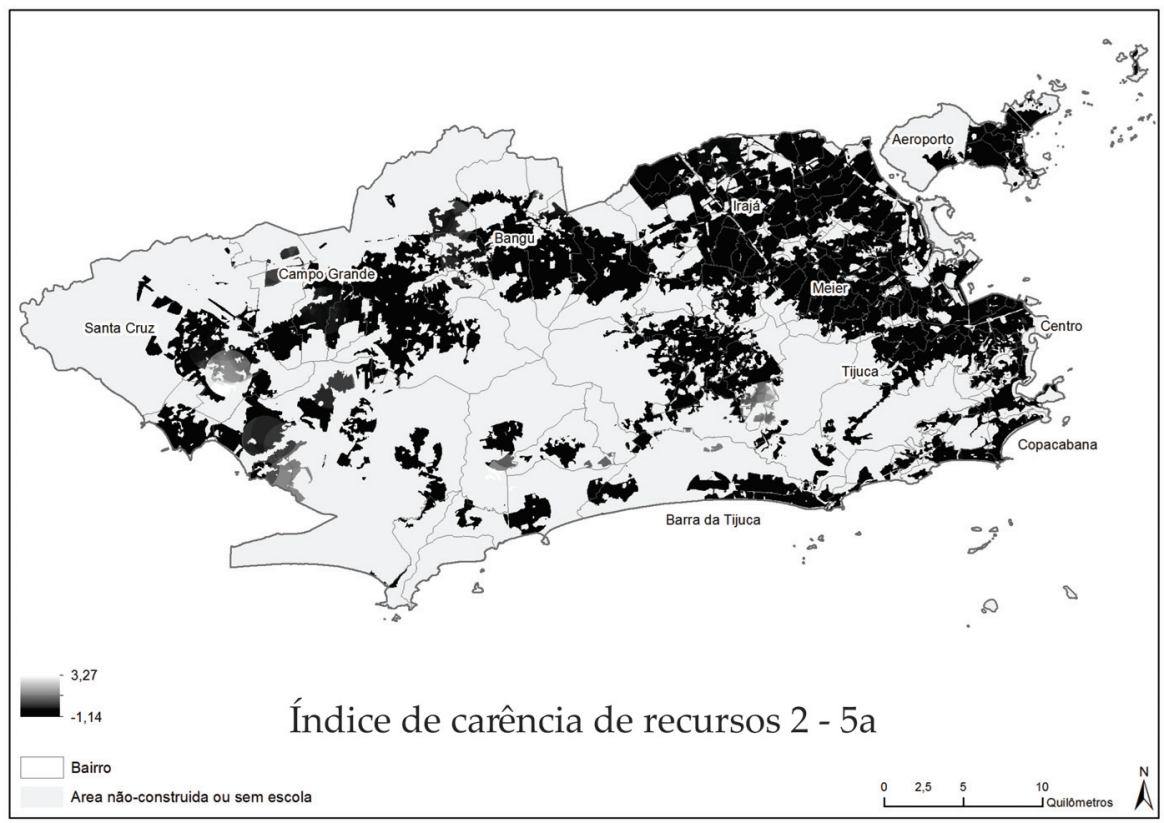

Fonte: Prova Brasil 2011. Elaboração dos autores. 


\section{Mapa 13}

Problemas que prejudicam o funcionamento da escola na cidade do Rio de Janeiro - $9^{\circ}$ ano do ensino fundamental

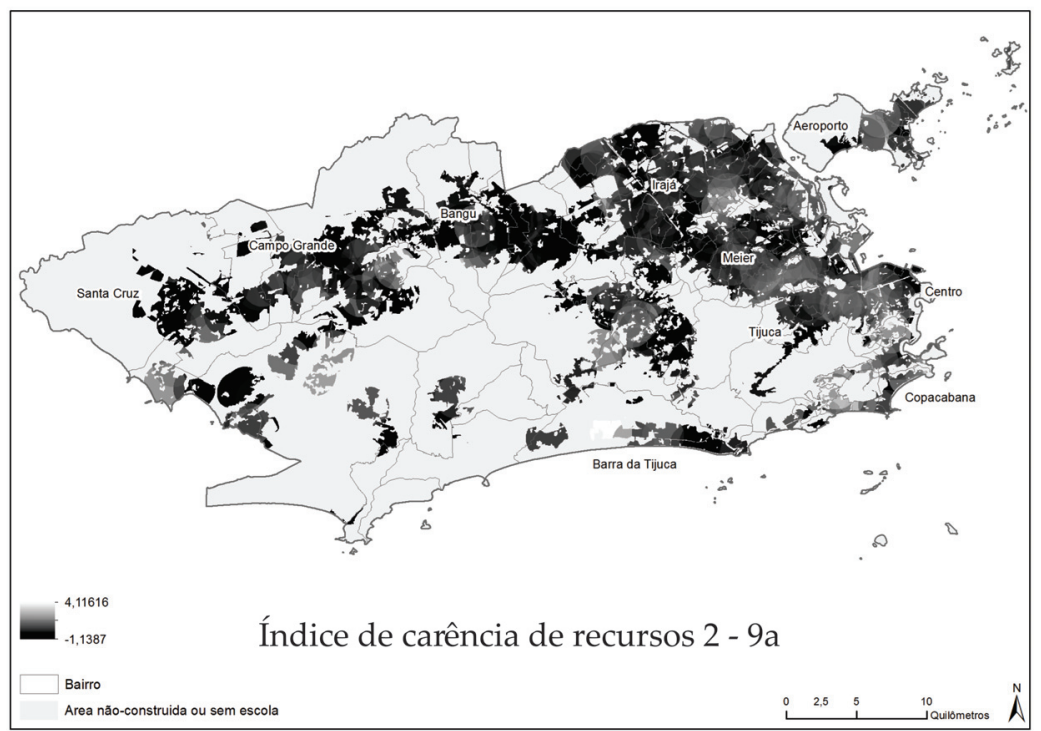

Fonte: Censo Escolar 2011. Elaboração dos autores.

\section{Mapa 14}

Índice de Infraestrutura das escolas na cidade do Rio de Janeiro - Séries iniciais do ensino fundamental

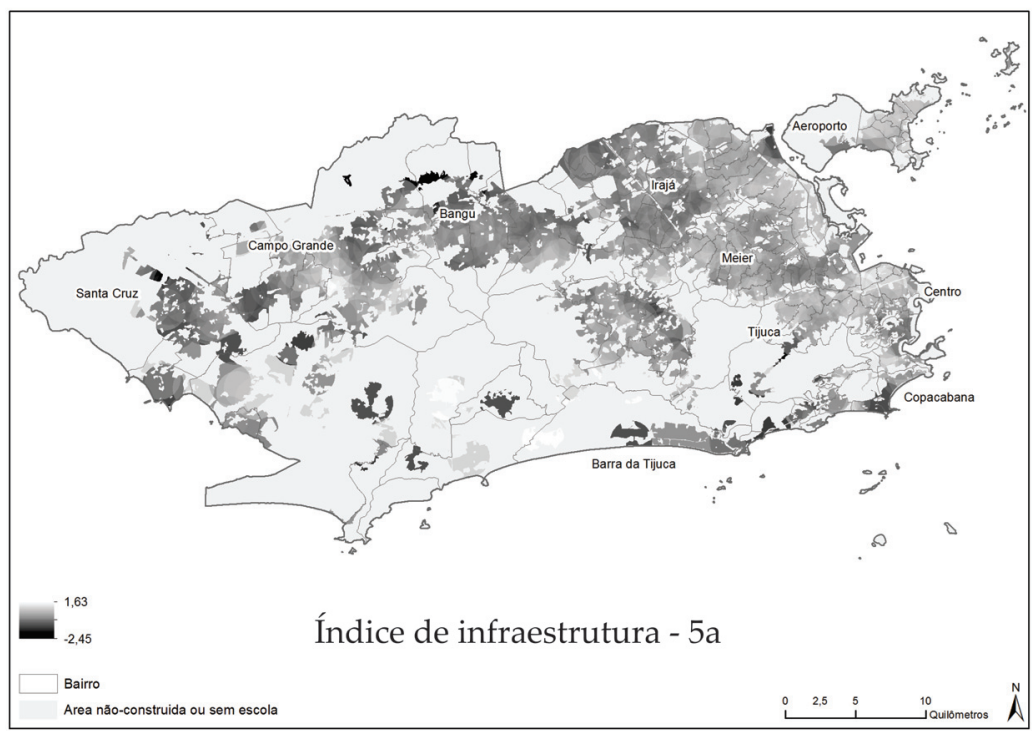

Fonte: Censo Escolar 2011. Elaboração dos autores. 


\section{Mapa 15}

Índice de Infraestrutura das escolas na cidade do Rio de Janeiro - séries finais do ensino fundamental

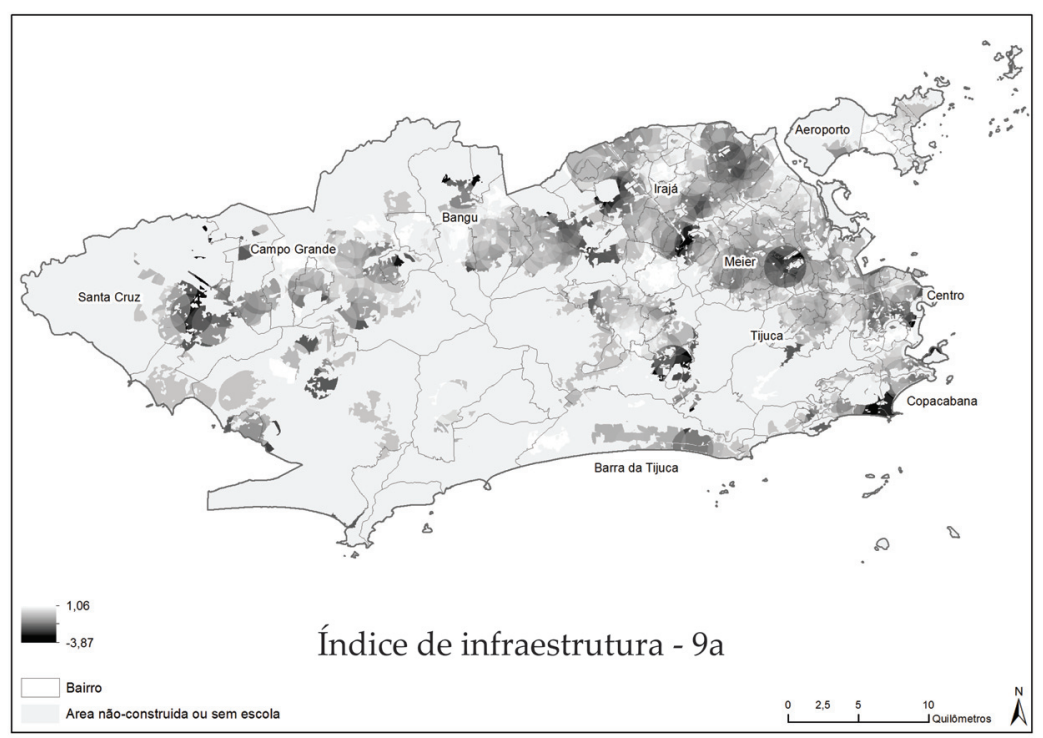

\section{Mapa 16}

Distribuição da porcentagem de professores que possuem altas expectativas em relação aos alunos na cidade do Rio de Janeiro $-5^{\underline{0}}$ ano do ensino fundamental

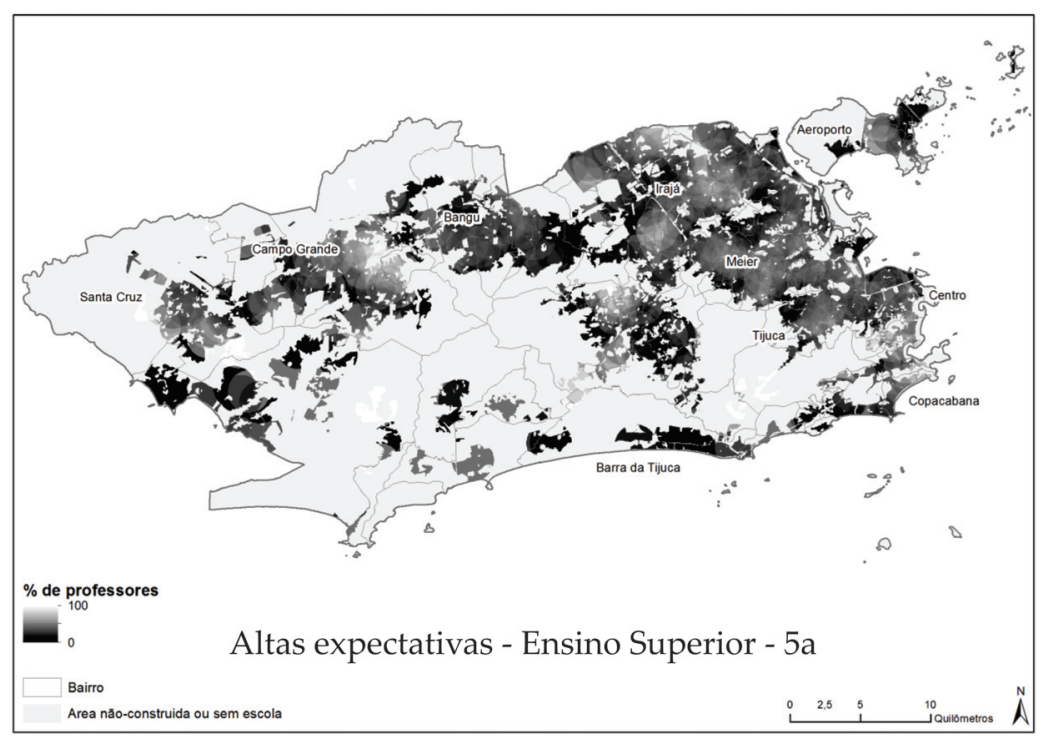

Fonte: Prova Brasil 2011. Elaboração dos autores. 


\section{Mapa 17}

Distribuição da porcentagem de professores que possuem altas expectativas em relação aos alunos na cidade do Rio de Janeiro $-9^{\circ}$ ano do ensino fundamental

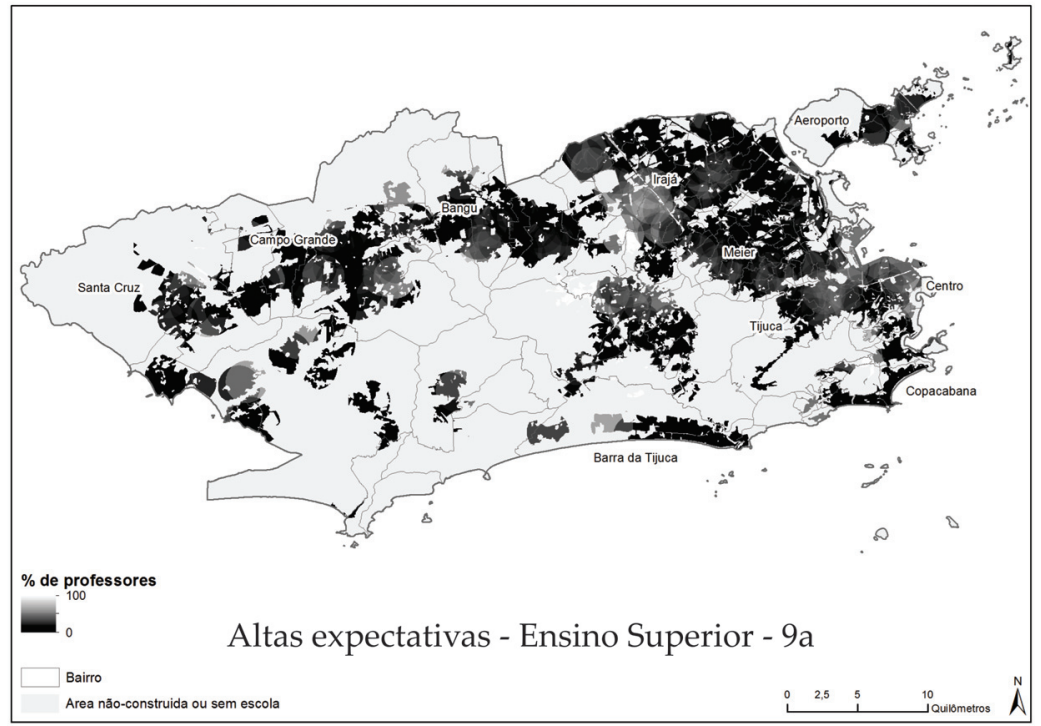

Fonte: Prova Brasil 2011. Elaboração dos autores

Um dos mecanismos institucionais tratados pela literatura sociológica refere-se aos modelos de papel social de adultos que trabalham nas instituições do entorno. Dentro dessa abordagem, os mapas 16 e 17 apresentados (5ㅜㅡ ano e $9^{\circ}$ ano do ensino fundamental, respectivamente) indicam a porcentagem de professores que acreditam que todos ou quase todos os seus alunos entrarão na universidade. Impressiona a distribuição homogênea na cidade. Infelizmente, para um sentido negativo. Na maior parte da cidade, a porcentagem de professores com altas expectativas sobre seus alunos é extremamente baixa. Ressalta-se uma semelhança perversa entre os mapas de IDS e da educação dos pais. Preocupante mesmo é ver como as expectativas dos professores são menores quando analisamos os dados do $9^{\circ}$ ano do ensino fundamental.

\section{Considerações finais}

Ao considerar a extensa bibliografia que trata da geografia de oportunidades educacionais em centros urbanos, duas questões parecem ser prementes para as políticas que visam diminuir desigualdades educacionais: (i) Como garantir acesso a escolas e maior igualdade na distribuição de recursos entre elas (infraestrutura, recursos humanos e práticas eficazes)? (ii) Como garantir escolas menos segmentadas e/ou segregadas? 
O artigo apresentou uma discussão teórico-metodológica capaz de evidenciar as microdesigualdades educacionais presentes nas grandes cidades. Acreditamos que as ferramentas de geoprocessamento, a partir de um Sistema da Informação Geográfica (SIG), possam auxiliar o planejamento de políticas públicas com foco na garantia de maior igualdade de oportunidades educacionais, ao permitirem a observação da distribuição de alunos e de recursos entre as escolas. Essas técnicas também podem permitir a observação de tendências ao longo do tempo, decorrentes de mudanças demográficas ou de políticas públicas.

No entanto, é importante frisar que a combinação entre planejamento urbano e políticas educacionais e mesmo o uso de técnicas de geoprocessamento já estão presentes em algumas políticas educacionais adotadas no contexto brasileiro. Como exemplo, podemos citar políticas que focalizam áreas vulneráveis e o uso de ferramentas de georrefenciamento para a realização de procedimentos de matrícula. Contudo, se essas experiências parecem capazes de abordar a primeira questão (garantia de acesso e distribuição de recursos entre as escolas), parecem menos efetivas no que diz respeito à garantia de menor segregação escolar.

Nas últimas décadas observamos a proliferação de políticas geograficamente focalizadas, como as "áreas de educação prioritárias" (ZEP) na França e os "Territórios Educativos de Intervenção Prioritária" (Teip) em Portugal. Tais políticas priorizam escolas localizadas em áreas vulneráveis e que atendem a classes populares, a partir do incentivo à elaboração de projetos para alcançar maior eficiência das escolas e a alocação de aporte de recursos para sua realização. A concepção de "áreas prioritárias" também está presente em recentes programas elaborados no contexto brasileiro, como, por exemplo, o PDE-escola do Governo Federal e o programa Escolas do Amanhã da Secretaria Municipal do Rio de Janeiro. Se, de um lado, políticas com foco geográfico trazem mais recursos e/ou a ampliação da jornada para escolas em áreas segregadas, de outro, correm o risco de gerar efeitos colaterais não intencionados. Por exemplo, a estigmatização das escolas em zonas prioritárias está por traz dos processos de evitment scolaiere descritos por Ben Ayed (2012), que podem levar a maior segregação escolar.

No contexto brasileiro, também observamos o uso de ferramentas de georreferenciamento para planejar a distribuição de alunos entre as escolas da(s) rede(s) pública(s). Por exemplo, a Secretaria de Estado do Paraná utiliza um sistema de matrícula por georreferenciamento que consiste no mapeamento de escolas e alunos ${ }^{6} \mathrm{e}$ na distribuição dos alunos de acordo com a proximidade de casa e a disponibilidade de vagas. Tal sistema garante aos alunos acesso a uma vaga na escola mais próxima de suas residências. No entanto, esse sistema, ao impor uma restrição geográfica às matrículas, pode potencializar o impacto da segregação residencial sobre a segregação escolar. 
Como argumenta Frankenberg e Lee (2002), políticas de dessegregação escolar, com foco na distribuição mais equilibrada de alunos entre as escolas, enfrentariam barreiras impostas pela composição social e racial dos bairros, pela disponibilidade de transporte público e pelas distâncias possíveis a serem percorridas pelos alunos. No limite, as políticas educacionais para combater segregação escolar precisariam ser acompanhadas por políticas urbanas de longo prazo de dessegragação das grandes cidades.

\section{Notas}

1. Estes trabalhos partem da decisão da Suprema Corte dos EUA, conhecida como "Brown v Board of Education", pelo fim da separação de escolas para brancos e negros. A partir dela, diversos distritos escolares implementaram planos de dessegregação que foram acompanhados, ao menos nestes distritos, pela composição de escolas mais integradas.

2. Os autores se referem às reformas introduzidas pelo School Standards and Framework Act, de 1998, que fortaleceram a capacidade de autoridades educacionais locais (Local Educational Authorities) de usar o critério de distância entre casa-escola para distribuir alunos entre as escolas e reduziram o papel da school choice e mecanismos de mercados introduzidos pela reforma de 1988.

3. Os autores atribuem esse padrão aos critérios de alocação de professores e diretores adotados pelas redes municipal e estadual de Educação.

4. O desempenho escolar dos alunos foi medido a partir da nota na prova de Língua Portuguesa do Sistema de Avaliação de Rendimento Escolar do Estado de São Paulo (Saresp).

5. Tais indicadores foram calculados a partir de dados do Sistema Mineiro de Avaliação de Educação Pública (Simave).

6. O georreferenicamento da residência dos alunos é feito a partir da conta de energia elétrica de suas residências (postes de luz).

\section{Referências}

AINSWORTH, J.W. Why does it take a village? The mediation of neighborhood effects on educational achievement. Social Forces, Oxford, v. 81, n. 1, p. 117-152, 2002.

ALVES, M.T.; FRANCO, F.C.J. A pesquisa em eficácia escolar no Brasil: evidências sobre o feito das escolas e fatores associados à eficácia escolar. In: BROOKE, N.; SOARES, J.F. Pesquisa em eficácia escolar: origem e trajetórias. Belo Horizonte: UFMG, 2008.

ALVES, F.; LANGE, W.; BONAMINO, A. A geografia objetiva de oportunidades educacionais na cidade do Rio de Janeiro. In: RIBEIRO, L.C.Q. et al. (Org.). Desigualdades urbanas, desigualdades escolares. Rio de Janeiro: Letra Capital, 2010. p. 67-89.

BEN AYED, C. As desigualdades socioespaciais de acesso aos saberes: uma perspectiva de renovação da sociologia das desigualdades escolares? Educação E Sociedade, Campinas, v. 33, n. 120, p. 783-803, 2012. 
COSTA, M.; KOSLINSKI, M.C.; COSTA, L. Educational inequality and social stratification in Brazil. In: PEILIN, G.M.K.; SCALON, C.; SHARMA, K.L. (Org.). Social Stratification in the Bric Countries: change and perspective. 1. ed. Singapore; London; New Jersey: World Scientific Publishing, 2012. p. 445-462

BROOKE, N.; SOARES, J.F. Pesquisa em eficácia escolar: origem e trajetórias. Belo Horizonte: UFMG, 2008.

BROOKS-GUNN, J.; DUNCAN, G.J.; ABER, J.L. (Ed.). Neighborhood poverty: context and consequences for children. New York: Russell Sage Foundation, 1997. v. 1.

COLEMAN, J. et al. Equality of educational opportunity. Washington, DC: Office of Education; US Departament of Health, Education and Welfare, 1966.

CRANE, J. The epidemic theory of ghettos and neighborhood effects on dropping out and teenage childbearing. The American Journal of Sociology, Chicago, v. 96, n. 5, p. 1226-1259, 1991.

DUNCAN, G.J. Families and neighbors as sources of disadvantage in the schooling decisions of black and white adolescents. American Journal of Education, Chicago, v. 103, n. 1, p. 20-53, 1994.

ELLEN, I.G.; TURNER, M.A. Does neighborhood matter?: assessing recent evidence. Housing Policy Debate, Alexandria, v. 8, n. 4, p. 833-866, 1997.

ÉRNICA, M.; BATISTA, A.A.G. A escola, a metrópole e a vizinhança vulnerável. Cadernos de Pesquisa, São Paulo, v. 42, n. 146, p. 640-666, 2012.

FLORES, C. Segregação residencial e resultados educacionais na cidade de Santiago do Chile. In: RIBEIRO, L.C.Q.; KAZTMAN, R. (Ed.). A cidade contra a escola: segregação urbana e desigualdades educacionais em grandes cidades da América Latina. Rio de Janeiro: Letra Capital, 2008. p. 145-179.

FRANKENBERG, E.; LEE, C. Race in American public schools: rapidly resegregating school districts. Los Angeles: Civil Rights Project; UCLA, 2002

GORARD, S.; TAYLOR, C.; FITZ, J. Schools, markets and choice policies. London: Routledge Falmer, 2003

GALSTER, G.C.; KILLEN, S.P. The geography of metropolitan opportunity: a reconnaissance and conceptual framework. Housing Policy Debate, Alexandria, v. 5, n. 1, p. 7-43, 1995.

JENCKS, C.; MAYER, S. The social consequences of growing in a poor neighborhood. In: LYNN, L.E.; MCGEARY, M.G.H. (Ed.). Inner-city poverty in the United States. Washington, DC: National Academy, 1990. p. 111-186 
KAZTMAN, R. Seducidos y abandonados: elaislamiento social de los pobres urbanos. Revista de la Cepal, n. 75, dez. 2001.

KAZTMAN, R. Territorio y cohesión social en las grandes ciudades de América Latina. In: 36º Encontro da Anpocs, 36., Águas de Lindóia, MG, 2012.

KOSLINSKI, M.C.; ALVES, F. Novos olhares para as desigualdades de oportunidades educacionais: a segregação residencial e a relação favela-asfalto no contexto carioca. Educação \& Sociedade, Campinas, v. 33, n. 120, p. 783-803, 2012.

KOSLINSKI, M.C.; LASMAR, C.; ALVES, F. Observatório Educação e Cidade: algumas hipóteses sobre a relação entre território e oportunidades educacionais. E-metropolis, n. 8, p. 8-20, 2012. Disponível em: <http://www.emetropolis.net/index.php?option=com _ edicoes\&task=artigos\&id=20\&lang $=\mathrm{pt}>$

KOSLINSKI, M.C. et al. Quase mercado escolar em contexto de proximidade espacial e distância social: o caso do Rio de Janeiro. In: Colóquio Luso-Brasileiro de Sociologia da Educação, 2., Portalegre, Portugal, 2010.

LOGAN, J. Resegregation in American public schools? Not in the 1990s. Albany, NY: Mumford Center for Comparative Urban and Regional Research, 2004.

LÓPEZ, N. A escola e o bairro. Reflexões sobre o caráter territorial dos processos educacionais nas cidades. In: RIBEIRO, L.C.Q.; KAZTMAN, R. (Ed.). A cidade contra a escola: segregação urbana e desigualdades educacionais em grandes cidades da América Latina. Rio de Janeiro: Letra Capital, 2008. p. 327-362.

PADILHA, F. et al. As regularidades e exceções no desempenho no Ideb dos municípios. Estudos em Avaliação Educacional, v. 23, n. 51, p. 58-81, 2012.

PINTO, J.M.R. A política recente de fundos para o financiamento da educação e seus efeitos no pacto federativo. Educação E Sociedade, Campinas, v. 28, n. 100, p. 877-897, 2007.

RIBEIRO, L.C.Q. Cidade desigual ou cidade partida? Tendências da metrópole do Rio de Janeiro. In: RIBEIRO, L.C.Q. (Org.). O futuro das metrópoles: desigualdades e governabilidade. Rio de Janeiro: Revan; Fase, 2000. p. 62-98.

RIBEIRO, L.C.Q.; KAZTMAN, R. (Ed.). A cidade contra a escola: segregação urbana e desigualdades educacionais em grandes cidades da América Latina. Rio de Janeiro: Letra Capital, 2008.

RIBEIRO, L.C.Q.; KOSLINSKI, M.C. Fronteiras urbanas da democratização das oportunidades educacionais: o caso do Rio de Janeiro. In: RIBEIRO, L.C.Q. et al. (Org.). Desigualdades urbanas, desigualdades escolares. Rio de Janeiro: Letra Capital, 2010. p. 121-153. 
RIBEIRO, L.C.Q. et al. (Org.). Desigualdades urbanas, desigualdades escolares. Rio de Janeiro: Letra Capital, 2010.

SÁTYRO, N.; SOARES, S. A infraestrutura das escolas brasileiras de ensino fundamental: um estudo com base nos censos escolares de 1997 a 2005. Texto para Discussão, Brasília, DF, n. 1267, 2007.

SMALL, L.M.; NEWMAN, E. Urban poverty after the truly disadvantaged: the rediscovery of family, neighborhood, and culture. Annual Review of Sociology, Palo Alto, v. 27, p. 23-45, 2001.

SOARES, J.F. Índice de Desenvolvimento da Educação de São Paulo - Idesp: bases metodológicas. São Paulo em Perspectiva, São Paulo, v. 23, n. 1, p. 29-41, 2009.

SOARES, S.; SÁTYRO, N. O impacto da infraestrutura escolar na taxa de distorção idade-série das escolas brasileiras de ensino fundamental - 1998 a 2005. Texto para Discussão, Brasília, DF, n. 1338, 2008.

TAYLOR, C.; GORARD, S. The role of residence in school segregation: placing the impact of parental choice in perspective. Environmentand Planning A, v. 33, n. 10, p. 1829-1852,2001.

TORRES, H.; GOMES, S. Desigualdade educacional e segregação social na Região Metropolitana de São Paulo. Novos Estudos Cebrap, São Paulo, n. 64, p. 132-140, 2002.

TORRES, H.G. et al. Educação na periferia de São Paulo: ou como pensar as desigualdades educacionais? In: RIBEIRO, L.C.Q.; KAZTMAN, R. (Ed.). A cidade contra a escola: segregação urbana e desigualdades educacionais em grandes cidades da América Latina. Rio de Janeiro: Letra Capital, 2008. p. 145-179.

WILSON, W.J. The truly disadvantaged: the inner city, the underclass and public policy. Chicago, Il: University of Chicago, 1987.

Recebido em 15 de junho de 2013.

Aprovado em 16 de julho de 2013. 